\title{
Socio-economic rehabilitation programmes of LEPRA India - methodology, results and application of needs-based socio-economic evaluation
}

\author{
V. PRABHAKARA RAO, I.R. RAO \& D.D. PALANDE \\ LEPRA India, Krishnapuri Colony, West Marredpally, Secunderabad \\ 26, India
}

\begin{abstract}
Summary There is now a better understanding of the scope and process of rehabilitation. The approach recognizes the impact of leprosy on the individual, aims to understand the needs and concerns of those affected, their families and community in the rehabilitation process, and that aims to restore the person to normal social life. LEPRA India has undertaken socio-economic rehabilitation (SER) activities in its projects in Andrah Pradesh and Orissa States in India with a holistic approach that has been evolutionary, developmental and participatory. A SER Officer (SERO) was posted to each project. A plan was formulated by the SERO with participation of all project staff. The main emphasis of the programme was on active participation of the affected person in the rehabilitation process. A needs-assessment study was conducted in the target population using a semi-structured questionnaire. Information was elicited about social and economic status, before and after the disease, and the current rehabilitation needs of the persons affected. The next step was meeting the needs through interventions by the SER staff. The impact of the programme on restoration of social and economic status of the affected persons was analysed. The paper stresses the importance of assessing the needs of persons affected by leprosy, structuring a rehabilitation programme with the active participation of the affected person and evaluating the impact of the interventions in restoring normal social and economic life.
\end{abstract}

\section{Introduction}

The objectives of the socio-economic rehabilitation (SER) programme undertaken by LEPRA India are:

- Economic empowerment of affected persons by enhancing their productivity.

- Restoration of social status with appropriate socio-economic interventions.

- Restoration of human dignity and improvement in the quality of life of the affected persons through their active participation and empowerment of their communities.

- Networking and partnership with various agencies related to this programme.

The SER programme has been incorporated into seven existing projects by appointing

Correspondence to: V. Prabhakara Rao 
SER Officer (SERO) at the project level working with the active involvement of all field staff.

The SEROs were appointed on the basis of the following skills and competencies:

- Skills in identifying the rehabilitation needs of the leprosy affected persons using appropriate tools.

- Intervention skills such as casework, group work and community organization.

- Experience in interview and observation techniques.

- Skills in conducting group discussions, case studies and in participatory micro-level planning.

- Skills in monitoring and evaluation.

- Team management skills.

With the appointment of SEROs in 1997, the SER activity was implemented as a structured activity within the overall context of ongoing leprosy programmes.

\section{Materials and methods}

The study was divided into three parts: needs assessment, interventions and evaluation of impact.

NEEDS ASSESSMENT STUDY

To assess the SER needs of persons affected by leprosy and implement interventions acceptable to them and their families, a needs assessment study was conducted initially in three projects.

The study was conducted among persons having grade 1 (G1) and grade 2 (G2) disabilities. There were 2280 persons with G1 and 2667 persons with G2 disabilities. Lists of all these persons were prepared by age and sex. Ten percent were selected for this study by stratified random sampling, 220 with G1 and 258 with G2. A structured interview schedule was devised separately for the $\mathrm{G} 1$ and $\mathrm{G} 2$ categories of persons to elicit information both qualitatively and quantitatively on the socio-economic consequences of leprosy and rehabilitation needs. A workshop was conducted for staff in each project on SER activities, relevance of needs assessment and methodology of administering the interview.

\section{DEVELOPING SER INTERVENTIONS}

Initial and follow-up workshops were conducted for Project Officers (POS) and SEROs by experts in the field of rehabilitation to acquaint them with the methodology of programme implementation, the inputs needed and the importance of sustained follow-up.

Orientation and re-orientation training programmes were conducted for the field staff to explain their role in the SER implementation.

Paramedical workers carried out the initial assessment of needs of affected persons with the help of a structured questionnaire and informal discussions with contacts. These findings were used to prepare lists of persons needing different rehabilitation interventions. These were referred to SEROs who conducted in-depth assessments and prepared proposals in 
consultation with Village Rehabilitation Committees (VRC) for review by the Rehabilitation Coordination Committee (RCC) in the project. These committees are constituted at the level of village or at clusters of villages. The committee has 10-15 members drawn from local leaders, informal leaders (members from youth club/women groups), school teachers, Anganwadi workers, village health workers and the clients. The paramedical worker is the convener of the committee which meets once a month, reviews needs of clients, suggests suitable schemes of assistance, monitors regular repayment of loans and explores avenues of procurement of raw material and sale of finished products.

\section{IMPACT ASSESSMENT}

A sample of 120 clients who received assistance with SER interventions were administered a structured questionnaire to assess the impact of the intervention in improving the quality of life.

\section{Results}

\section{NEEDS ASSESSMENT}

The findings of the needs assessment are tabulated in Table 1.

It was observed that discrimination within families was less in persons with G1 disability compared to those with G2 disabilities. Only $6 \%$ in G1 reported that they were discriminated against compared to $19 \%$ in G2. The discrimination against women in G2 was significantly greater $(25 \%)$ than against men with the same grade $(18 \%)$

The social problems identified were analysed by age and sex. The reported problems included problems at work, in education, in marriage, attendance at family and community functions and behavioural change in contacts.

The following observations can be made:

- Persons with G1 disabilities did not face problems in the work situation, and were

Table 1. Family support and discrimination experienced by persons with grade 1 and 2 disabilities

\begin{tabular}{|c|c|c|c|c|c|c|c|c|c|c|}
\hline & \multirow[b]{2}{*}{ Grade } & \multicolumn{3}{|c|}{ Male } & \multicolumn{3}{|c|}{ Female } & \multicolumn{3}{|c|}{ Total } \\
\hline & & $16-45$ & $>45$ & Total & $16-45$ & $>45$ & Total & $16-45$ & $>45$ & Total \\
\hline \multicolumn{11}{|l|}{ Family supports } \\
\hline & G1 & 70 & 63 & 133 & 36 & 38 & 74 & 133 & 74 & 207 \\
\hline & G2 & 69 & 72 & 141 & 38 & 31 & 69 & 141 & 69 & 210 \\
\hline \multicolumn{11}{|l|}{ Family discriminates } \\
\hline & G1 & 4 & 3 & 7 & 4 & 2 & 6 & 7 & 6 & 13 \\
\hline & G2 & 14 & 11 & 25 & 17 & 6 & 23 & 25 & 23 & 48 \\
\hline \multicolumn{11}{|l|}{ Total } \\
\hline & Gl & 74 & 66 & 140 & 40 & 40 & 80 & 140 & 80 & 220 \\
\hline & G2 & 83 & 83 & 166 & 55 & 37 & 92 & 166 & 92 & 258 \\
\hline
\end{tabular}


accepted in the wider family circles and the community. However, $7 \%$ of females with G1 disabilities expressed problems with marriage and education.

- Among persons with G2 disabilities, $7 \%$ faced problems in their work situation, $5 \%$ in education and marriage, while $8 \%$ felt discriminated in community functions and $7 \%$ experienced behavioral changes among contacts.

- About $22 \%$ of females in G2 grade, who were discriminated within the family, did not have any problems in work situation, marriage and education and acceptance in family and community functions. This needs to be studied further in relation to the extent of disabilities and functional capabilities as it implies that females in G2 category are more discriminated within the family than outside in the community.

It was observed from an analysis of the economic problems of persons in G1 and G2 disabilities that:

- In the G1 category only $10 \%$ had adequate income to support their families (2\% among females). $64 \%$ had marginal income while $25 \%$ do not have any income and were dependent on family members. However, only $16 \%$ reported a fall in income due to leprosy. The income level of the population was generally low and persons affected by leprosy also had low incomes. Twelve percent of the respondents felt that they needed to change their occupation to prevent damage to their hands and feet.

- In the G2 category, only $7 \%$ had adequate income (2\% among females), $57 \%$ had marginal income, while $36 \%$ were dependent on family members. A fall in income was reported by $44 \%$ of persons in this category. Thirty-three percent felt that they needed to change their occupation to prevent further damage to their hands and feet.

- In the G1 group, $98 \%$ of females were dependent on their family, and in the G2 group 97\% were dependent. Women contribute to income by their work in agriculture and other household work, but their work was not considered as income generating and their status was therefore considered as dependent. Thirty-nine percent of the females in the G2 group felt the need to change their traditional occupation for protection of hands and feet.

Preferences for rehabilitation made by the participants were analysed:

- In both the G1 and G2 groups, 30\% preferred assistance for small business ventures, $22 \%$ preferred assistance for dairy and poultry, while only $2 \%$ preferred self-supporting ventures such as sewing machines, weaving and rickshaws. Such occupations were considered to have little market and hence the beneficiaries did not prefer them.

- In the G1 group, $21 \%$ desired old-age/widow pensions and 7\% desired assistance for housing. In $\mathrm{G} 2$, the corresponding data were $25 \%$ and $9 \%$.

- The lack of awareness among clients about different schemes of assistance by the Government of India, the absence of an intervening agency to espouse their cause and the lack of initiatives from local leaders to represent their needs were the main reasons why many clients did not show inclination to opt for more self-supporting schemes.

\section{SER INTERVENTIONS}

Forty VRCs were formed on an experimental basis to understand how they function. It was found that 20 committees were functioning regularly.

A brief summary of SER interventions developed during a period of 2 years is presented in Table 2. 
Table 2. SER interventions and their beneficiaries

\begin{tabular}{llrrr}
\hline & & \multicolumn{2}{c}{ Beneficiaries } \\
\cline { 3 - 5 } Scheme & \multicolumn{1}{c}{ Schemes } & Male & Female & Total \\
\cline { 3 - 5 } & & 55 & 9 & 64 \\
1 & Loans from Government & 105 & 25 & 130 \\
2 & Housing (Government) & 161 & 150 & 311 \\
3 & Pensions (OAP/DP/WP) Government & 44 & 23 & 67 \\
4 & Philanthropists & 37 & 10 & 57 \\
5 & Loans from LEPRA India & 1 & 1 & 4 \\
6 & Educational support (LEPRA India) & 416 & 219 & 635 \\
7 & Service in NGO & & \\
8 & Total & & & 2 \\
& & & &
\end{tabular}

Over 1300 scheme proposals submitted to the government are being processed for different types of assistance.

A focused approach was adopted for providing assistance to women affected by leprosy, since it was observed in the needs assessment study that over $90 \%$ of women affected by leprosy were largely dependent on other members of the family. Apart from the interventions for 219 women beneficiaries, special training programmes were conducted for women in the projects to develop skills to undertake income-generating schemes.

A handloom weaving training centre was established in one of the projects where women are exclusively trained for 10 months in weaving. Ten women completed their training and loans are being processed to help them establish their own cottage units. An electronic watch-assembling unit has been started. Women affected by leprosy but having dexterity of fingers are trained in assembling watches. The scheme is supported by Government. A training programme for ten women has been organized in making incense sticks.

\section{IMPACT ASSESSMENT}

Of the 120 interviewed, 53 were restored to initial economic status, 58 reported marginal improvement and nine no improvement. The reasons for lack of improvement in economic status of the nine persons were analysed and found to be: business ran into loss because of credit transactions, death of milk cattle, and addiction of beneficiaries to alcohol. Some of the important reasons for marginal improvement were seasonal business with average yield, gestation period of certain interventions (such as rearing of goats and sheep). These may show improvement in due course.

Of the 120 beneficiaries who were interviewed, it was found that 26 had social problems in addition to economic problems. Of the 26,18 reported restoration to initial economic status, two marginal improvement and six no improvement. All the six individuals who did not show any improvement in social rehabilitation had significant deformities and were not accepted either by family or society. In the case of marginal improvement, two individuals were accepted by the family but did not have normal acceptance by their community members. 


\section{Discussion}

Several constraints are faced in the implementation of the SER programme. The main issues were:

- There is lack of awareness among people about various schemes of assistance available from different government departments. The SER teams have to first acquaint the people about these schemes and explain the benefits before they can decide to accept them.

- The procedures for economic assistance that are offered by the system result in delay in extending the assistance required by the clients.

- The apathy and lack of participation by the community in the process of rehabilitation of persons affected by leprosy. This requires a good deal of persuasive and motivational efforts from the SER teams.

- Some of the projects included in this presentation were located in very difficult to reach tribal areas, which imposes limitations on access to the enablers and the beneficiaries in tapping the resources, utilization and marketing the finished produce.

- Since the SER programme has been introduced recently in ongoing leprosy projects, there is a backlog of persons affected by leprosy in need of different socio-economic interventions.

Since many aspects of SER are related to the disability, a strong prevention of disability component in each project will help greatly in minimizing the need for rehabilitation.

For strengthening community participation and ownership of the programme, the concept of formation of VRCs, which has been initiated, needs to be incorporated and expanded. The community has to assume the responsibility of sustaining the schemes of assistance provided to the beneficiaries.

SER activity has to be considered as an integral part of the overall strategy of each leprosy project. The programme can deliver results only if every member of the team participates in it from the initial stage of needs assessment to reintegration of the beneficiary into the normal environment.

A strong educational component in the programme, whether in the current vertical set-up or in the ensuing integrated set-up, is still essential. Correct attitudes and practices about leprosy in all sections of the society are essential to prevent the process of 'dehabilitation' and extend the required support to those in need of rehabilitation. Leprosy elimination is envisaged within a short span of time but the persons affected by the disease are considerable in numbers and need to be assisted to lead a life with dignity.

\section{Acknowledgement}

The authors express their thanks to the POs, SEROs and other staff of each project for the invaluable assistance rendered by them in preparing this paper.

\section{References}

${ }^{1}$ ILEP. Guidelines for the social and economic rehabilitation of people affected by leprosy. ILEP, 1999.

2 Frist T. 'Don't treat me like I have leprosy' A guide for overcoming prejudice and segregation. TALMILEP, 1996.

3 Jayaraj Devdas and Salim. Social work in leprosy eradication. ILF, 1990. 